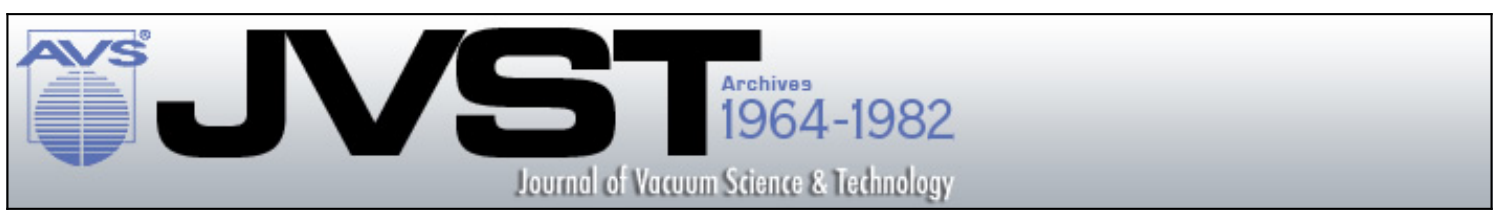

\title{
Current Flow through Thin Insulating Films: Basic Principles and Device Applications
}

Carver A. Mead

Citation: Journal of Vacuum Science \& Technology 8, 98 (1971); doi: 10.1116/1.1316370

View online: http://dx.doi.org/10.1116/1.1316370

View Table of Contents: http://scitation.aip.org/content/avs/journal/jvst/8/1?ver=pdfcov

Published by the AVS: Science \& Technology of Materials, Interfaces, and Processing

\section{Articles you may be interested in}

Holographic diagnosis: Basic principles and applications

J. Acoust. Soc. Am. 120, 3212 (2006); 10.1121/1.4788138

Insulator issues in alternating-current thin-film electroluminescent devices

J. Appl. Phys. 90, 2711 (2001); 10.1063/1.1388598

Leakage current models of thin film silicon-on-insulator devices

Appl. Phys. Lett. 72, 1199 (1998); 10.1063/1.121012

Perceptual coding of wideband audio signals: Basic principles and current applications

J. Acoust. Soc. Am. 100, 2601 (1996); 10.1121/1.417611

Oscillatory Tunneling Current through ThinFilm Insulating Barriers in a Magnetic Field J. Appl. Phys. 34, 3556 (1963); 10.1063/1.1729257

\section{ADVERTISEMENT}

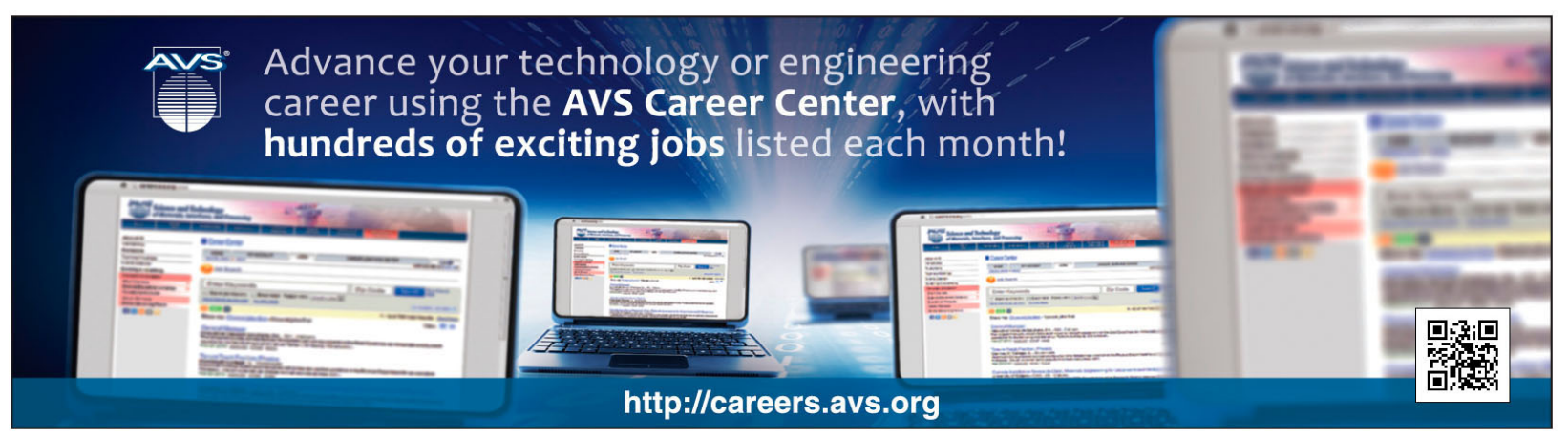




\section{Current Flow through Thin Insulating Films: Basic Principles and Device Applications}

\section{Carver A. Mead}

California Institute of Technology, Pasadena, California

The fundamental physics underlying current flow through thin insulating films is reviewed, with emphasis placed on those experiments central to the identification of the dominant current flow mechanism in a given structure. Recent data obtained on metal-insulator-metal structures incorporating single crystal thin films represents unambiguous observation of both thermionic emission and tunneling. Device applications of thin films are also summarized.

\section{Oxidized Silicon Surface}

Peter V. Gray

General Electric Research and Development Center, P. O. Box 8, Scheneclady, New York 12301

Surface parameters play an important if not dominant role in limiting the performance of many semiconductor devices. The research effort which has been directed toward semiconductor surfaces in recent years has greatly improved our understanding of oxidized silicon and has provided a logical basis for modern semiconductor processing techniques. Relevant surface phenomena include contamination and imperfections in the oxide layer, impurity redistribution in the silicon near the oxide, and additional electronic states at the oxide-silicon interface. The successes of the MOS method of surface characterization will be reviewed. 